\title{
Noise and the Voice: exploring the thresholds of vocal transgression
}

\author{
Aaron Cassidy \\ The voice can say much more and, when it \\ speaks the body, cannot help but speak of other things. \\ -Douglas Kahn ${ }^{1}$
}

Noise in vocal artistic practice poses a fascinating problem of definitions. Establishing the thresholds of vocal noise is surprisingly difficult, as the conventional boundaries of noise are not of much use when it comes to the voice. From a spectral, acoustical, Helmholtzian standpoint, almost all vocalization is, to greater and lesser degrees, noise. Unvoiced, unpitched consonants are, by definition, noise, and most voiced consonants include significant noise components. Indeed, even the purest sung or spoken vowels contain aperiodic, non-harmonic components: "the flow of air through the oscillating narrow slit between the vocal folds creates the possibility for turbulent noise, similar to the way we form consonants such as 's' by creating a narrow place in the vocal tract and forcing air through it." ${ }^{.2}$ Signal processing notions of noise are similarly unhelpful in establishing the boundaries of vocal noise practice, as they rely principally on intentionality and meaning, on some presumption of an attempt towards communicative utterance. While this approach is potentially useful from a linguistic standpoint, for the work under discussion here, which is principally artistic rather than

1 Douglas Kahn, Noise Water Meat (Cambridge: MIT Press, 1999), 291.

2 Perry R. Cook, "Pitch, Periodicity, and Noise in the Voice," in Music, Cognition, and Computerized Sound: an introduction to psychoacoustics, ed. Perry R. Cook (Cambridge: MIT Press, 1999), 202. Cook goes on later to say, "there is some noise that cannot be controlled by the singer and, as in vibrato, there is always some amount of noise no matter what the singer does to eliminate it" (204). 
principally textually communicative, the signal itself may well be noise, or at least intentionally noisy, and the notion of "irrelevant or unwanted data" seems out of place. Simon Reynolds provides a third possibility, fascinating but equally unhelpful in establishing the boundaries of noise, proposing that "noise occurs in moments, tiny breakages and stresses dispersed all over the surface of music, all kinds of music." That is, vocal noise appears in the microscopic cracks in the voice, in the way that vocalists use their voices "for the gratuitous voluptuousness of the utterance itself."

This chapter aims to examine vocal artistic noise practice as a performed act of transgression. It explores questions of otherness, of uniqueness and individuality, of revelation of the natural and the performance of the unnatural, and of noise as a decentering, deterritorializing act. And it investigates why we find vocalized noise often so deeply unsettling, strange, or disturbing that we instinctively laugh out of embarrassment or discomfort, while similar instrumental or electronic sounds rarely carry the same baggage.

Despite the proliferation of writing about noise and noise music in recent years, there is surprisingly little written about noise and the voice. It is particularly surprising because the voice has played an important role in theories of noise for the last one hundred years. Consider Luigi Russolo's classifications of the six families of noise in The Art of Noises from 1913. In all but the fifth category ("Noises obtained by beating on metals, woods, skins, stones, pottery, etc."), the voice is present throughout, at least implicitly: roars, hissing roars (type 1), whistling, hissing, puffing (type 2), whispers, murmurs, mumbling, muttering, gurgling (type 3), screeching, humming, buzzing (type 4), shouts, screams, shrieks, wails, hoots, howls, death rattles, sobs (type 6). All are clearly vocal, despite the fact that Russolo's manifesto was principally a call to arms for mechanical, instrumental, and electronic music

3 Simon Reynolds, "Noise," in Audio Culture, ed. Christoph Cox and Daniel Warner (New York: Continuum, 2004), 58. 
making. ${ }^{4}$ Indeed, though Russolo's categories use the voice as an analogy or a descriptive reference, most noise practice since his time has principally been music for machines of one sort or another.

To that end, this chapter focuses specifically on the unaccompanied, unadorned voice. There are of course numerous examples of musicians and artists who use their voices as part of a noise practice that includes electronic modification and distortion, from the early work of Henri Chopin to Trevor Wishart to more recent practitioners such as Maja Solveig Kjelstrup Ratkje ${ }^{5}$ or indeed much of the vocalization in the "noise music" genre. I am intentionally avoiding discussion of that kind of approach here primarily because it seems necessary, in this context, to direct the discussion not toward the use of the voice in noise but instead toward noise in the voice itself. That is, this chapter is not about noise practice that incorporates the voice; it is about the noise of the voice used in artistic practice and establishing what the thresholds of vocal noise might be. (The only extension of the voice that appears in the repertoire below is the microphone.) Despite that limitation, the scope is fairly broad, including examples from free improvisation, grindcore, sound poetry, performance art, notated music, and theater.

\section{Vocal Noise, Otherness, and Limits of the Body}

There is a moment in Antonin Artaud's Les malades et les médecins (1946) that I find particularly fascinating. ${ }^{6}$ The opening few minutes are typical

4 Luigi Russolo, “The Art of Noises," excerpted in Audio Culture, 13.

5 As Marie Thompson puts it, "Ratkje cracks open the voice to find a mouth full of wires." Marie Thompson, "Music for Cyborgs: the affect and ethics of noise music," in Reverberations: the philosophy, aesthetics and politics of noise, ed. Michael Goddard, Benjamin Halligan, and Paul Hegarty (London: Continuum, 2012), 217.

6 Antonin Artaud, Deux Émissions De René Farabet (France: André Dimanche Éditeur, 1995). The audio is also available on YouTube (http://www.youtube.com/watch?v=RaQ-KG4cjrI) and ubuweb (http:// www.ubu.com/sound/artaud.html). An unattributed translation of the text can be found here: http:// www.falseart.com/antonin-artaud-les-malades-et-les-medecins/. 
of Artaud's approach to vocalized text: odd, singsong, hesitant, faltering, mannered, with a consistent grit and brittleness in the voice, and occasional higher pitched, childlike squeaks and falsetto blips.Just after the three-minute mark, the text, which had been bizarre and mangled but was nonetheless text, is briefly replaced by a shocking, gripping, horrifying series of indecipherable, chicken-like squawks and yelps. It takes only a few seconds, a microscopic percentage of the five-minute overall duration, but it is astonishing. A line is immediately crossed from text that is about, however loose or strange, to a state of otherness that is both revelatory and distancing. ${ }^{7}$ For me, the fascination lies in the immediacy of this leap into otherness. The voice continually pushes against the threshold, but, as though pushing against a spring that suddenly collapses, the moment the threshold is crossed a seemingly insurmountable gap into otherness is formed. It is a transgressive moment that opens a fissure that cannot be closed.

This sense of otherness is a common thread in vocal noise. The spaces that it opens are strange, funny, bewildering, embarrassing, shocking, and enthralling; they seem to draw us in as listeners to a peculiarly personal place, which can be both intimate and inviting or disturbing and repelling. There is a vulnerability to this kind of vocalization that is quite distinct from similar sounds made through non-vocal means.

The voice comes to us as an expressive signal announcing the presence of a body and an individual. ... The voice is the very core of an ontology that balances presence and absence, life and death, upon an unsteady and transformative axis. The voice comes to signify through a slippery and unforgettable semantics the movements of consciousness, desire, presence, while also riveting language with bodily materiality. ${ }^{8}$

7 Douglas Kahn describes an account of Artaud's screaming during a lecture on "The Theatre and the Plague." "Afterward among friends, Artaud protested, "They always want to hear about; they want to hear an objective conference on "The Theatre and the Plague," and I want to give them the experience itself, the plague itself, so they will be terrified, and awaken." Noise Water Meat, 349 (emphasis added).

8 Brandon LaBelle, "Raw Orality: Sound Poetry and Live Bodies," Voice: Vocal Aesthetics in Digital Arts and Media, ed. Norie Neumark, Ross Gibson, and Theo van Leeuwen (Cambridge: MIT Press, 2010), 149. 
This link between the voice and the body is made particularly evident in the extraordinary work of the British vocalist Phil Minton. A leading vocal improviser, Minton has generated a repertoire of nearly inexplicable extended techniques that push at the limits of what is possible with the voice. I have seen numerous concert reviews with lists of verbs attempting to describe what Minton does, but none come close to explaining what the sounds actually are, predominately because those descriptors usually rely on references to a known collection of sounds (belching, growling, Donald Duck) that dramatically minimize and reduce the actual palette of vocalizations in his work, which are quite a bit stranger.

I am struck by the disparity between how I listen to Minton's work when I can see him, either in person or on video, and when I cannot. ${ }^{9}$ It reveals a curious gap between the pure physiology of the voice and the physiology of the voiced body, that is, the gap between the actual sound production mechanism of larynx, breath, tongue, and mouth versus "the voice" as the representation of human physicality and expression. Sonically, we hear the voice, but we hear such an otherworldly voice that it is often strangely disembodied. The further away the vocalizations get from sung or spoken vocal production, the more this phenomenon is magnified, to the point that all that is left is "grain," a pure, vocal materiality. ${ }^{10}$ But in performance, these sounds are coupled to Minton's twisted, contorted bodily motions and to a most extraordinary set of facial expressions, which often look similar to the smeared and distorted faces of a Francis Bacon painting: as Deleuze puts it, "the forces of deformation, which seize the Figure's body and head, and become visible whenever the head shakes off its face." ${ }^{11}$ Though he typically

9 For example, http://www.youtube.com/watch?v=wCS4vUym0_8 or http://www.youtube.com watch?v=g2OLYsOlHNA.

10 Roland Barthes, “The Grain of the Voice," Image-Music-Text (New York: Hill and Wang, 1978), 182, 188.

11 Gilles Deleuze, Francis Bacon: The Logic of Sensation, trans. Daniel W. Smith (Minneapolis: University of Minnesota Press, 2004), 53. 
sings seated, generally with his hands comfortably on his knees, his singing is bodily, the voice only the final extension of a deep physicality.

The human voice readily becomes its Other through vocalization. Conversely, the face retains its visible base onto which are mapped the mannered means for shaping itself into facial variations. The pulled face, the disfigured face, will always be marked by its human physiology. The voice - through the multiplicity of its invisibility—will always locate itself in adverse directions beyond the origin of its generation and production. Like the thrown voice coming from somewhere else, the voice sings, speaks, screams, and states its residence in Otherness. ${ }^{12}$

Minton's work also draws attention to a phenomenon common to vocal noise more generally. We hear struggle in his singing. In works such as "Wreath" or "Blasphemy," from the collection A Doughnut in Both Hands, we hear the raw physicality and extremity of some of Minton's more severe vocal practice. ${ }^{13}$ Both works have moments in which vocalization dissolves into actual gagging and coughing as Minton gasps for breath or chokes on his own spit and apparently, in the case of "Wreath," vomit. In "A Good Song" or "Psalm of Evolution 1," from the same disc, the form of the improvisation seems driven at least partially by the amount of time Minton can maintain any one sound-we hear him "reset" periodically, the limits of the body pushing back against his insistence towards sounds at the threshold of tension, pressure, and breath. We can hear that he is forced to stop, to swallow, to catch his breath, to recover at least temporarily from the strain placed on the vocal mechanism.

One of the critical thresholds of otherness and transgression in noise vocalization is the sense of physical tension, discomfort, constriction, and even pain present in the voice, and, more significantly, the way in which

12 Philip Brophy, "Vocalizing the Posthuman," in Neumark, Gibson, and Van Leeuwen, eds., Voice, 361.

13 Phil Minton, A Doughnut in Both Hands: Solo Singing 1975-1981 (Emanem 4025, 1998). 
those sounds are elongated, magnified, and intensified. It is their extremity and their relentlessness that carries them into the realm of noise. It creates an initial empathy with the listener, an awareness of risk, and then pushes that threshold of risk up to and occasionally beyond the limits of the body. Georges Aperghis's Récitation 14, for example, asks the singer to breathe in, hold the breath for as long as possible, and then speak a repeating, looping rhythmic cell with cross-cutting French and English texts, with a tempo that slows consistently from a quarter note pulse of 120 to 40 BPM over the course of 18 repetitions, before the whole process begins again with a new breath. ${ }^{14}$ The final cell of the 18 ends with four eighth-note rests-an excruciating three-second pause, all available breath by this point well since expelled and the brain starved of oxygen - so the repetition begins not with the careful, deep breath that starts the piece but instead with a gasping, fearful breath of self-preservation before, again, pausing as long as possible before beginning the rhythmic looping text. The singer is asked to repeat the process "ad libitum," though few singers seem to manage it more than twice. The process dramatically affects the kind of vocal production employed. The singer, carefully rationing breath, typically uses a halting, constricted sound, rather than the more playful, balletic sung and spoken text common to the rest of the Récitations collection. The pressure and restriction is palpable, and, as is the case with the Minton examples above, establishes an immediate sense of empathy with the listener and an awareness of the very real physical vulnerability present in the work. ${ }^{15}$

The work of the performance artists Ulay and Abramović goes even further. Much of their work during their twelve-year partnership in the 1970s and 80s included investigations and interrogations of bodily limits,

14 Georges Aperghis, Récitations pour voix seule (Paris: Editions Salabert, 1982).

15 I am thankful to the soprano Peyee Chen (who, incidentally, managed three repetitions) for her very helpful insight into the experience of performing the piece. 
often invoking extreme bodily fatigue, pain, and risk of death. ${ }^{16}$ The piece $A A A A A A$ (1978) provides an ideal example of the thresholds of noise in the voice:

We are facing each other both producing a continuous vocal sound. We slowly build up the tension, our faces coming closer together until we are screaming into each other's open mouths. ${ }^{17}$

As with Artaud's Les malades et les médecins, the threshold here is immediately apparent and helps to establish how aspects of both otherness and physical limitations contribute to an awareness of noise in the voice. What begins as a controlled, almost sung yell moves closer and closer to the threshold of noise. Within a few minutes, the strain placed on the voice through the yelling starts to introduce small quivers and yodels, the voice increasingly out of the control of the vocalist. The end of each yell begins to reveal a raspy, abrasive roughness in the voice, the internal discomfort and pain in the throat inching closer to the aural surface. After several minutes of continuous yelling, Ulay's voice is the first to break- he coughs instinctively and involuntarily, and even after he regains his vocal composure we see him swallow noticeably after the end of the next yell in a feeble attempt to soothe the throat with saliva. As the screams intensify, the need to reset and recover intensifies as well, the scene increasingly poignant as the two vocalists move closer and closer together, their noses now almost touching. By the fifth minute, their heads start to shake during the yells, and the time between yells gets longer, the yells shorter and louder, the pain in the voice even more apparent. It is here where the threshold seems to be crossed into a transgressive space of otherness. Perhaps

16 See for example Relation in Time (1977), in which the two sat back-to-back with their hair tied together for 16 hours, Rest Energy (1980), in which the two stand face to face holding a drawn bow and arrow between them, or Breathing In/Breathing Out (1977), their open mouths locked together, one breathing out as the other breathes in as they slowly poison each other with carbon dioxide until they eventually collapse, unconscious.

17 Ulay (Uwe Laysiepen) and Marina Abramović, AAA AAA (1978), accessed April 11, 2013, http:// www.youtube.com/watch?v=iAIfLnQ26JY. The text is Abramović's voice-over introduction. 
it is simply the place at which almost anyone else would stop. And perhaps it is also this moment that reveals the otherness of the performer: our empathy, our befuddlement, our discomfort, and our instinctual embarrassment each contribute to the them-ness of the vocalists. The transgressive act reveals their humanity, but it also reinforces that they are not us.

The grit and vocal fatigue continue to intensify, the yells become increasingly bodily. Nine minutes in, Ulay gives up, unable to yell anymore, while Abramović continues for another fifteen seconds or so on her own. We see and hear the moment when the voice fails, where it is simply no longer possible to continue to vocalize.

For Artaud the idea of asphyxiation, which he employed throughout his career, ran across breath, air, and social space as a means to mediate between life and death corporeality and the suffocating effects of society. Indeed, asphyxiation and the scream formed the parameters of the complex of this exchange - one a withholding of breath/air/space, the other its ultimate activation, both determined by total purpose.... What was once the actual body has been left intact and rendered fantasmic, reduced to a double that exports a few organs into the functioning, vacant body when called for. These organs no longer retain their normal functions but have been reduced to serving only as signposts to locate the movements of breath and void in the vacated, actual body. ${ }^{18}$

It is a very real noise, an authentic noise. There is a social space that is transgressed (verifiable even with a quick glance at the hundreds of comments on the YouTube video of $A A A A A A)$ as well as a transgression of the physical

18 Kahn, Noise Water Meat, 351-52. 
limits of the voice. ${ }^{19}$ Its noise confronts us with otherness in large part through the uncontrollable, instinctual, bodily reaction and resistance, its separation from the controlled space of the sung and spoken voice.

The articulate singing voice that projects an image of the conscious humancapable of language and social expression - is the voice masquerading as a living force. Its recourse to language remits it to symbolically celebrate its distance from death.... But that same remit blocks the articulate singing voice from confronting voice at its elemental, its guttural, its expulsive. Posthuman vocalization thus refers precisely to how the voice returns to breath. ${ }^{20}$

Vocal noise artists draw on this sense of otherness, and indeed on the identification of physical tension and pain, amplifying and reveling in the noise of the broken voice. The Canadian group Tunnel Canary, one of the earliest practitioners of noise rock, exemplifies this practice:

I first got the idea for the style of the vocals at an early Vancouver punk gig when a bunch of punk girls were fooling around with a stage mic between sets. One of them (it may have been Mary Jo, bass player for the Modernettes) let out a loud scream. I thought this was the most interesting and powerful event of the evening. Too bad, I thought, that it couldn't have gone on longer.... I decided to experiment with this idea and asked Ebra (then my girlfriend) if she could scream for an extended period of time. She tried and was incredible.

19 As Norie Neumark writes, "to allow [the voice] to rise in a scream is to open the body to be read as hysterical, infantile, out of control, uncivilized. The scream is the sort of improper vocal gesture that proper bourgeois subjects learn not to emit." Norie Neumark, "Introduction: The Paradox of Voice," in Neumark, Gibson, and Van Leeuwen, eds., Voice, xxviii.

20 Brophy, "Vocalizing the Posthuman," 362. 
A screaming, angry female (Earth Mother taking her revenge) voice over radical, improvised electronic sounds-thus Tunnel Canary was born. ${ }^{21}$

The transgression exists largely in the artistic practice of funneling into a more or less natural noise-in this case a scream, in the case of Phil Minton a gravelly, squeaky, broken, or multiplied voice-and magnifying the noise, exploding it out to the surface and extending it to a breaking point.

\section{Vocal Noise as Nomadic Space}

Language has a territorializing function. It establishes boundaries and relationships, hierarchies, and connections through short- and long-term memory. Noise on the other hand is a fundamentally deterritorializing phenomenon, what Deleuze and Guattari might call a "local space of pure connection." 22 Indeed its noisiness lies principally in its destabilizing, its upending of communicative norms and hierarchies.

Here, there are no longer any forms or developments of forms; nor are there subjects or the formation of subjects. There is no structure, any more than there is genesis. There are only relations of movement and rest, speed and slowness between unformed elements, or at least between elements that are relatively unformed, molecules and particles of all kinds. ... We call this plane, which knows only longitudes and latitudes, speeds and haecceities, the plane of consistency or composition (as opposed to

21 Nathan Holiday, “Tunnel Canary," Museum of Canadian Music, accessed April 12, 2013, http:// www.mocm.ca/Music/Artist.aspx?ArtistId=104558\&RoomId=57, emphasis added. Holiday's account of the formation of the band also includes the following amusing anecdote: "I remember a funny incident at one of the first performances where two policeman thought Ebra was either deranged or having a seizure and approached her very cautiously; they were terrified, you could see it in their faces. When they finally asked her what was wrong, and to calm down, she told them that she was singing. They got very mad and told us to get the hell out of here and don't come back."

22 Gilles Deleuze and Félix Guattari, A Thousand Plateaus (Minneapolis: University of Minnesota Press, 1987), 493. 
the plan(e) of organization or development). It is necessarily a plane of immanence and univocality. ${ }^{23}$

Deleuze and Guattari refer to this phenomenon in many parallel wayssmooth space, haptic space, the plane of consistency, etc.- - each emphasizing the local, immediate, and the unbounded. It seems an ideal description of noise more generally and vocal noise specifically. ${ }^{24}$

Sound poetry revels in this decentered ambiguity. The work of The Four Horsemen, a Canadian performance collective active in the 1970s, for example, explores a vocal poetic practice that foregrounds an untethered, scrambled, non-semantic verbal communicative space. ${ }^{25}$ It is a communicative art, but an intentionally non-textual communication, in what the group's founder, Steve McCaffery, describes as an "intermedia experience ... generated on the liminal zones of theatre, music and poetry." 26 The group's work reorients vocal communication to a principally bodily rather than textual practice, including yells, screams, grunts, and various physical manipulations of the mouth, as well as unpredictable mutations and distortions of localized phonemic content through elongation and repetition. This approach is similarly seen in the solo work of McCaffery and Paul Dutton (another member of The Four Horsemen). For example in Dutton's "Mercure" or in the collection Mouth Pieces: Solo Singing, or in McCaffery's performances of the concrete poem Carnival, a common technique is grabbing, stuttering, and repeating a short

23 Deleuze and Guattari, $A$ Thousand Plateaus, 266.

24 See Paul Hegarty "A Chronic Condition: Noise and Time," in Goddard, Halligan, and Hegarty, eds., Reverberations, for a similar discussion about this deterritorializing function of noise with regard to time and form.

25 See for example this excerpt of Ron Mann's 1982 film Poetry in Motion, http://www.youtube.com/ watch?v=843O0bTVKHQ.

26 Steve McCaffery, "Sound Poetry - A Survey," from Sound Poetry: A Catalogue, ed. Steve McCaffery and bpNichol (Toronto: Underwich Editions, 1978). Reproduced at http://www.ubu.com/papers/ mccaffery.html, accessed April 19, 2013. 
fragment of text or a phonemic subcomponent of a word, or, similarly, taking some small subcomponent of the production of a word or simple vocal sound and extending and stretching it, both revealing its internal, microscopic sonic reality and turning it into something else altogether. ${ }^{27}$

We might identify sound poetry as a cultural arena granting witness to the movements of certain bodies on the way in and out of communicative acts. It seeks to rivet language with new sonorous materiality and in doing so refashions the self's relation to vocality and processes of signification. ... [I] n seeking other relations to speech, it retools the mouth by incorporating an oral calisthenics, concocting conditions for other linguistic acts, literally seeking to bypass the regular movements of orality for new configurations, and turning the mouth into the site of production for other semantics. That is, sound poetry yearns for language by rupturing the very coherence of it. ${ }^{28}$

Gil J Wolman's work is even more extreme in its abandonment of the territorializing features of language, leaving behind even the basic phonemic content of vowels and consonants. Active in the Letterist movement in the 1950s, Wolman developed the concept of the "megapneume" (mégapneumie), "a poem of great breath or vigor, a mega-breath, ... a striking form of physical poetry." ${ }^{29}$ In "La mémoire," perhaps the most absolute example, the content of the megapneume is exclusively the sound of breath: inhaling and exhaling, a quivering and pulsation of breath, modifications of the size and shape of the

27 Paul Dutton, "Mercure" (http://www.youtube.com/watch?v=zCaCHyj4ozk) and Mouth Pieces: Solo Soundsinging (OHM Editions, OHM/AVTR 021, 2000), also available at http://www.ubu.com/sound/ dutton.html. Steve McCaffery "Carnival," live performance from Instal Glasgow, 2009, accessed July 31, 2013, http://www.youtube.com/watch?v=Z5sB_YvvSS4.

28 LaBelle, "Raw Orality," 150.

29 Frédéric Acquaviva, "Wolman in the Open," Museu d'Art Contemporani de Barcelona, accessed April 19, 2013, http://www.macba.cat/PDFs/acquaviva_eng.pdf. Italics in original. 
mouth to color and filter the pitch and contour of the breath, a distinction between breath through the nose and breath through the mouth, and changes in the speed and duration of breathing. ${ }^{30}$ It is quintessential vocal noise, both in its sonic character and in its deterritorialized, localized communicative space. Its noise is, as Deleuze and Guattari put it, a nomadic line:

A line that delimits nothing, that describes no contour, that no longer goes from one point to another but instead passes between points, that is always declining from the horizontal and the vertical and deviating from the diagonal, that is constantly changing direction, a mutant line of this kind that is without outside or inside, form or background, beginning or end and that is as alive as a continuous variation - such a line is truly an abstract line and describes a smooth space. ${ }^{31}$

Devoid of any lingering linguistic ciphers, our focus is drawn to the breath, the body, the voice. Its materials are a scrambling of codes that force a locallevel listening, an ambiguity of intention and relationship. The saxophonist Dror Feiler describes this phenomenon in noise music more generally:

Our attention funnels into the work's singular moments, and once we realize the "NOISE MUSIC" is not here to fulfill a macro-structural objective, it becomes something that ends in itself. Instead of singular "NOISE" existing for the abstract achievements of the whole, the whole is composed to throw us back onto the horns of the "NOISE." ... Every "NOISE" in the music takes on a specific meaning, and no clear hierarchy exists between them.... Yet equality does not slip into interchangeability, for each "NOISE" in the music remains painfully particular. ... As soon

30 Gil J Wolman, "La mémoire," originally released on Revue OU No.33,1968. Also available at http:// www.youtube.com/watch?v=372y4Cc7T08.

31 Deleuze and Guattari, A Thousand Plateaus, 297-98. 
as we encounter "NOISE MUSIC" we are engaged in a struggle to make some sense of what we hear. Unable to categorize the stimulus within any known musical genre, incapable of interpreting or recognizing sounds, and generally bereft of aesthetic orientation, the work commands our full attention. With our ear tuned and focused to hunt out some structure and reason in the work, micrologics emerge. ${ }^{32}$

Marie Thompson puts it similarly:

Noise music in general may be understood to be, quite literally, the musicalization of indiscernibility. Noise music relies on an exploitation of the grey area of contradiction; it lies on the fault line between music and non-music, wanted and unwanted, the pleasurable and grotesque, and so on, pulling in various, conflicting directions. ${ }^{33}$

This phenomenon takes on a slightly different form in the work of the German vocalist Ute Wassermann, whose chirruping, hooting ululations, glottal trills, and yodels are of a completely different sort than any of the other vocalists mentioned here so far. One of the things I find most fascinating about Wassermann's unique vocal technique is the very instrumental, and sometimes even electronic, implication of the soundworld. Unlike the work of Minton, The Four Horsemen, or Wolman, which relies on an approach to the voice that is pared down and often uncomfortably revelatory, this is a much more stylized, intimate, and seemingly controlled vocal practice. The destabilizing factor here is, at least in part, the result of the disconnect between the sound of Wassermann's fascinating, stunningly individual fluttering and our ability to connect those sounds to the mouth, to the voice. To be fair, most

32 Dror Feiler, "Exile as Noise - Noise as Exile," accessed April 19, 2013, http://www.tochnit-aleph. com/drorfeiler/exile.html.

33 Marie Thompson, "Music for cyborgs: the affect and ethics of noise music," in Goddard, Halligan, and Hegarty, eds., Reverberations, 215. 
of Wassermann's work is quite clearly vocal in its character and identity, but for my ears the moments that are most fascinating, and indeed the moments that seem to move into a realm of noise, are the moments in which the voice "goes beyond itself" into a much less identifiably vocal space.

Wassermann's piece "trill territory" on the solo CD birdtalking, for example, begins with a fairly simple timbral trill from the tongue on a single sustained pitch, initially a flipping of the front of the tongue as in the consonant "L." But very quickly — in fact in a matter of only a few seconds-the trill moves further and further back along the tongue into the back of the throat into an increasingly unusual, fascinating, and even befuddling flickering that is somehow less explicitly vocal. ${ }^{34}$ Similar processes are repeated frequently throughout the improvisation, with numerous sounds seemingly disconnected from the voice, the soundworld dissolving into the sounds of birds, of machines, of electronics. At the very least, our ability to "reverse engineer" the vocal aspect is seriously compromised in a way that is quite exceptional among vocalists. That is, if Phil Minton's "noise" comes largely from a disconcerting interrogation of the realities of the limits of the voice, Wassermann's "noise" comes from a disconcerting unreality, from a vocal practice that is so unique and specialized that it seems to disconnect itself from our ability to understand its sounds as vocal. To put it another way, its noise comes from the elimination of the "grain." 35

This noise is similarly deterritorializing. Its reinvention of the voice destabilizes and decenters the voice and dissolves the relationship between the voice and the normal referencing boundaries of language, song, or even the mouth on a purely physiological level. Wassermann's voice takes the mouth and tongue - or even in a more general sense the voice-as-body-

34 Ute Wasserman, birdtalking (NURNICHTNUR, 2006).

35 This apparent separation between sound and the physiological aspects of its production can be seen periodically in Wassermann's improvisation "Ute on the Marshes," in the film by Helen Petts made for the "Voice and the Lens" symposium at the Icon Gallery Birmingham, November 2012, accessed April 22, 2013, http://www.youtube.com/watch?v=aQcRpOh3LCc. 
and shifts, distorts, and reinvents the connections between these body parts themselves and between the body and the sounds that might result, creating a transgressive space that destabilizes our ability to connect the voice to sound.

\section{Vocal Noise as the Transgression of Uniqueness}

Vocal noise is about the individual body, about embodied otherness, about an individualized practice. But one of the great ironies of vocal noise is that, despite its seemingly personal, expressive qualities, its essential "noisiness" comes from the fact that vocal noise is, at its core, an erasure of uniqueness.

The voice in its normal state is one of the chief identifiers of individuality and personality, of one's particular person-ness.

What it communicates is precisely the true vital and perceptible uniqueness of the one who emits it. At stake here is not a closed-circuit communication between one's own voice and one's own ears, but rather a communication of one's own uniqueness that is, at the same time, a relation with another unique existent. ${ }^{36}$

Noise erases, or at least sidesteps, this uniqueness. On both a spectral and physiological level, this erasure comes from the fact that the vocal production of noise largely eliminates the resonating cavities that create vocal formants. In essence, it severs the connection between the voice and the body. Simple unvoiced consonants—s, sh, ch, k, t, etc.-require very little of the body for resonance. They are made almost entirely in the mouth, and their spectral content is created almost exclusively from the shape and size of the mouth and tongue. The difference between my "s" and your "s" is minimal. Vowels and voiced consonants, on the other hand, engage the body; their character,

36 Adriana Cavarero, For More Than One Voice: Toward a Philosophy of Vocal Expression, quoted in Neumark, "Introduction," xix. 
weight, and color come not only from the size and shape of the vocal folds, tongue, and mouth, but also from the chest, head, and bone structure of the speaker or singer. It is the uniqueness of these resonating cavities that gives a voice its identifiable connection with its emitter, and the noises of the voice sidestep this resonance and thus this identification. ${ }^{37}$

Vocal noise practice extends and plays on this gap. It lives in and exploits the transgressive "otherness" of what is, in a sense, a "voiceless" space. It is the space of the witness whose voice has been modified to hide his identity, a disembodied voice stripped of its primary identifying features. "Noise routes expression through the impersonal and indulges in a catastrophe of generic gestures." ${ }^{38}$ It is of course not only the noise of unvoiced consonants but also the performance of this otherness more generally that distinguishes vocal noise through its intentional, performed voicelessness. In the vocal performances of Valeri Scherstjanoi, for example, we have guttural grinding, clicks, hisses, and grumbles-it is a unique and personal artistic practice, but it is not the sounds themselves that are unique. It is instead the personally unidentifiable aspect of his vocalization that is the most definitively noisy. This intentional elimination of personality is a transgressive act similar to the art of Cindy Sherman, ${ }^{39}$ with its performed erasure of identity, or the work of Franko B, which is deeply personal and vulnerable and yet also an erasure of the personal in its whitewashed elimination of many of the defining features of face and

37 This sense of transgression may also have something to do with the evolutionary nature of consonants vs. vowels. Anne Karpf, in The human voice: the story of a remarkable talent (London: Bloomsbury, 2006), explains that consonants are evolutionarily much older than vowels, with human speech as we know it only about 100,000 years old as pitched vocalization only emerged through the relatively recent physiological dropping and lengthening of the larynx $(52-53,55)$. It is purely speculative, but perhaps this elimination of identifiably personal vocalization in noise is also an instinctual connection to a pre-modern, early evolutionary human state?

38 GegenSichKollektiv, "Anti-self: experience-less noise," in Goddard, Halligan, and Hegarty, eds., Reverberations, 194.

39 Cindy Sherman, Cindy Sherman: a play of selves (Ostfildern: Hatje Cantz, 2007). 
body, or the photography of Aziz + Cucher, which erases the defining features of the face (eyes, mouth, and nose) through digitally reconstructed "skin." 40

Ami Yoshida's improvisations are similar. ${ }^{41}$ Though her vocalizations are in many ways extraordinary in their sonic inventiveness-impossibly high shrieks, throat whistles, guttural grinding, piercing wails-they are also vocalizations that disconnect the voice from the body. These sounds are made in a microscopically small physical space in the throat. Like the squeal of air coming out of the pinched opening of a balloon, or like the unpredictable squawk from a clarinet reed, they are the noises not of their resonating chambers but instead of a tiny, compressed, pressurized space, here even smaller and even deeper into the recesses of the throat than the sounds found in Scherstjanoi's work. (This perhaps explains how, as a tall Caucasian male, I can manage to make similar sounds as Yoshida, a short Japanese woman.) Yoshida's performance mannerisms intensify this sense of separation, her eyes often either closed or looking up towards nothing in particular, which seems to draw our attention from the face and the torso inward towards the mouth, neck, tongue, and throat. ${ }^{42}$

This performed, noisy voicelessness is particularly present among vocalists whose work aims to make connections with the occult and with notions of evil. Take, for example, the vocal practice of "grindcore" (or to an even greater degree the subgenre of "pig squeal"). ${ }^{43}$ This gritty, gravelly vocal style revels in an ambiguous voicelessness. Its (literally) abrasive technique eliminates

40 Lea Vergine, Body Art and Performance: the Body as Language (Milan: Skira, 2000), 273, 276.

41 See, for example, Ami Yoshida, Tiger Thrush (Improvised Music from Japan, IMJ-504, 2003), also available at http://www.youtube.com/watch?v=bF4QszdBvl0.

42 "Power of Making; Ami Yoshida, Finding Voice - the Lingual," accessed July 25, 2013, http://vimeo. com/27164111.

43 There are numerous YouTube genre compilations available. See for example http://www.youtube. com/watch?v=iq_CajFb_5s or http://www.youtube.com/watch?v=k-3maJ3 for grindcore samples, or http://www.youtube.com/watch?v=3FpFkazuUmo for pig squeal. 
the controlled, harmonic vibration of the vocal folds and greatly hinders the ability to produce and pronounce words in any conventional sense (indeed, some grindcore foregoes any pretense of lyrics altogether, using the voice exclusively for its noise-making abilities). The technique subverts the natural timbre of the voice, replacing it with an intentionally personless, unidentifiable noise, an observation that seems to be reinforced by the numerous "how to" instructional videos and webpages on producing a "grindcore voice." ${ }^{4}$ Rather than an "Otherness," this vocal practice is a "No one-ness," and it is precisely this subversion of the personal individuality of the voice that crosses the threshold of noise.

Rather than trying to reconcile knowing and feeling, noise can help us to dissociate the commensurability of experience and subjectivity in a sense that exceeds the logic of framing. ... Noise, with its epistemic violence, counters the division between activity and passivity. By making us aware of our inability to decipher it, noise alienates us. ${ }^{45}$

Critically, this approach to noise production is highly intentional and, to a certain extent, even theatrical. The sounds produced are not actual screams, cries, or moans, and the more extreme the sound production employed, the less natural and innate the voice seems to be. That is, the voice is less personal and unique and less directly connected to its bodily creator. Norie Neumark uses the example of staged laughter:

it's the convulsions of broken voices that remind us how the voice normally coheres, despite its inherent tensions. Laugher, as it breaks into the voice, is an outburst of physiology and culture-both individually and

44 See, for example, http://www.wikihow.com/Perform-Grindcore-Vocals, http://www.youtube.com/ watch?v=Pq2Nrr8qkkM, or http://www.youtube.com/watch?v=UFtfCm8ogTM. (There are, of course, also parody videos: http://www.youtube.com/watch?v=Y4qSiM6Bgvg.) 
infectiously from one body to another. Laughter has both an immediate and mediated relation to voice. Because laughter is voice out of controlreleased at the edge of voice-controlled laughter, from the individual's forced laugh to the TV laugh track, can feel particularly disturbing. ${ }^{46}$

The "noise" of the voice, in this case, comes from the staged, inauthentic costume of the voice of the Other. It is not the sounds themselves that are noise, as such, but instead the act of taking the tiny breakages of the voice and staging them, elongating them, magnifying them. The discomfort arises through the transgression of making the accidental intentional. ${ }^{47}$

In general, what distinguishes noise in the voice is not so much a specific set of sonic characteristics or descriptors as much as a particular usage of those characteristics. Noise is behavioral, not absolute, and it exists in the thresholds of the voice as an expression of Self. It emerges in the spaces in which vocalization rejects the limits of the self, both physically and psychologically, and in which the articulating function of the voice is subsumed, either through the dissolution of linguistic structures or its timbral, personal individuality.

46 Neumark, "Introduction," xxvi-xxvii. One is also reminded of the Masahiro Mori's notion of the "uncanny valley" in robotics and artificial intelligence.

47 Note that this is different from the "self-subversion" discussed by Marie Thompson (quoting Simon Reynolds) in "Music for Cyborgs" (217-18). This is not a subversion of an imagined, invented, straw-man audience. 